\title{
Co-morbidity of attention deficit hyper activity disorder and associated factors among children with seizure disorder attending pediatric seizure clinic a cross-sectional study at Gondar University hospital (2016), northwest, Ethiopia
}

Haregewoin Mulat Sebhat ( $\nabla$ mediaug14@gmail.com )

University of Gondar https://orcid.org/0000-0001-6478-0075

Niguse Muluneh

university of Gondar

\section{Tewodros Eyasu}

university of Gondar

Research article

Keywords: Attention deficit hyper activity disorder, Seizure disorder, seizure clinic

Posted Date: February 17th, 2021

DOl: https://doi.org/10.21203/rs.3.rs-204774/v1

License: (c) (1) This work is licensed under a Creative Commons Attribution 4.0 International License.

Read Full License 


\section{Abstract}

\section{Background}

When attention deficit Hyperactivity Disorder (ADHD) presents in epileptic children, it makes the treatment complicated and the prognosis poor. Hence, understanding the magnitude of ADHD and associated factors would be important to have a policy intention towards these people and to design appropriate interventions. Therefore, the current study was conducted to determine co-morbidity of attention deficit hyperactivity disorder (ADHD) and associated factors in children with seizure disorders.

Methods

A hospital based cross-sectional study was conducted by taking 260children who had follow ups in the pediatric seizure clinic. The systematic random sampling technique was used to recruit participants. A structured, pretested and interviewer administered questionnaire which included questions on associated factors and standard disruptive behavioural disorder (DBD) rating scale was used to collect data. Data were coded, entered and cleaned by using the Epi-Data version 3.1 and exported to SPSS version 20 for further analysis. The multivariate binary logistic regression was used to cheek the association between independent and dependent variables. Variables with significant associations were identified on the basis of $\mathrm{OR}$, with a $95 \% \mathrm{Cl}$ and $\mathrm{p}$-value of $<0.05$ and considered as statistically significant.

\section{Result}

The prevalence of ADHD among epileptic children was found to be 115(44.2\%), with a confidence interval of (38.1-50.5), out of which only 3(2.6\%) were detected as having mental health problems by the clinician. The predominant subtype was inattentive type 96(61.1\%). Factors significantly associated with ADHD were male sex ( $A O R=2.70 \mathrm{Cl}: 1.46-4.97)$, family history of seizure disorder ( $A O R=2.42 \mathrm{Cl}: 1.26-4.65)$, family history mental illnesses (AOR=4.14 Cl: 1.76-9.68), sudden onset of seizure (AOR=2.37 Cl: $1.32-$ 4.27) and uncontrolled seizure (AOR=2.55 Cl: 1.41-4.61).

\section{Conclusion}

Attention deficit hyperactivity disorder was common among children with seizure disorders in the study area. Therefore, interventions that would address such factors would help to overcome further complications.

\section{Background}

Attention Deficit Hyperactivity Disorder (ADHD) is one of the most common mental disorders that develop in children and becomes apparent in preschool and early school years. It is characterized by pervasive and impairing symptoms of in-attention, hyperactivity, and impulsiveness that occur before 7 years of age(1) 
The prevalence of attention deficit hyper activity disorder (ADHD) in the general population ranges between $3 \%$ and $5 \%(2)$.The prevalence is much higher ranging from 8 to $77 \%$ among children with epilepsy than in the general population(3). The prevalence of ADHD among children with epilepsy in high income countries ranges from 23 to $70 \%(4,5)$.Clinical studies show that when ADHD presents in children with seizure disorders, it exerts its effect in the treatment and prognosis of the disorder. It can also have negative impacts on the affected child's behavioral, learning and social development. The studies suggest that $30-40 \%$ of children with epilepsy also present with $\operatorname{ADHD}(6,7)$. Despite this high prevalence, ADHD often remains unrecognized and left without treatment.

Studies identified that the magnitude of the problem in children with epilepsy varied across the globe such as, $6.9 \%$ in Korea(8), 42.2\% in China(9),27.7\% in Israel(10), 29.1\% in Brazil(11), $12 \%$ in UK(12), 28\% in Norway(13), 26.4\% in USA(14) and 60.4\% in Iran(15).

Another study conducted in central China showed that the magnitude of ADHD among children with epilepsy was $24.7 \%(16)$.

A recent study in the Indian tertiary medical center revealed that the co-morbidity of ADHD among epileptic children was $23 \%(17)$.

According to a study in Tanzania, the co-morbidity of ADHD among children with epilepsy showed that attention problem were more prevalent in children with epilepsy $53 \%$ compared with control groups (19\%) (18).

Previous studies revealed that age, sex, type of epilepsy syndrome $(6,16)$, earlier epilepsy onset, longer period of antiepileptic medication, epileptic children's receiving a combination of antiepileptic drugs(7), and the frequency of seizures (15)were the most common associated factors of ADHD among epileptic children.

Many of the studies were outside Africa, and the magnitude of ADHD among epileptic children in Ethiopia, particularly in the study area was poorly understood. Understanding the magnitude of ADHD and associated factors would be important to formulate policies and design appropriate interventions. Hence, the aim of this study was to assess the prevalence of co-morbidity of ADHD and associated factors among epileptic children who had follow ups at Gondar University hospital pediatric seizure clinic.

\section{Methods}

\section{Study setting and design}

A hospital based cross-sectional design was used to assess attention deficit hyperactivity disorder (ADHD) and associated factors among children with seizure disorders attending the pediatric seizure clinic of the University of Gondar referral hospital. Gondar is located about $723 \mathrm{~km}$ from Addis Ababa and 
$65 \mathrm{~km}$ to north of Lake Tana. The University of Gondar referral hospital provides tertiary care to the population of Gondar and its neighboring regions.

All Children attending the pediatric seizure clinic and aged between 6 and 17 years were taken as the source population while children who were available during data collection were considered as the study population. As per the information obtained from the pediatric seizure clinic, about 40 epileptic children with mothers or caregivers used to visit the clinic per week. The single population proportion formula with an assumption of $95 \%$ confidence level, a $5 \%$ margin of error and $50 \%$ prevalence and a $10 \%$ nonresponse rate were taken to determine the sample size as there were no similar studies in our country. Because the total population was less than 10,000 , correction formula was used to get the final sample size of 265 .

\section{Data collection method and instrument}

Data were collected from parents or caregivers by using the interview technique with the standard DBD rating scale for investigating the presence of ADHD. The scale consists of 45 items representing symptoms of Disruptive Behavior Disorders that are conduct disorder (CD), oppositional defiant disorder (ODD) and ADHD. Of the 45 items, only 18 were used in this study.

Children whose responses to six of the nine questions on hyper activity were "pretty much" or "very much" were considered as positive for the ADHD hyperactive sub type, while children whose responses to the same number of inattentive questions were "pretty much" or "very much" were considered as positive for the ADHD inattentive sub type. A structured questionnaire was developed to identify factors associated with $A D H D$, and patient charts were revised to get seizure related factors. The internal validity of the instrument was also checked (Cronbach alfa $=0.957$ ) and found to be acceptable.

\section{Data quality assurance and analysis}

The collected data were coded, entered and cleaned by using Epi-Data version 3.1 and exported to SPSS version 20. Frequencies and cross tabulations were used to summarize descriptive statistics of the data and tables and graphs were used for presentation. Bivariate logistic regression was first fitted to identify potential confounding factors and variables with p-values less than 0.2 were entered in to the multiple logistic regression model using the backward selection method to identify factors associated with depression. The adjusted odds ratio with a $95 \%$ confidence interval was calculated to report the strength and significance of the association.

Data quality was managed by training and appropriate supervision of data collectors by the principal investigator. A pre-test was done on 42 children at Feleg-hiwot hospital pediatric seizure clinic, Bahirdar. Appropriate modifications were made on the instrument after analyzing the pre-test result before the actual data collection.

\section{Results}




\section{Socio-demographic and family related factors}

A total of 260 children on follow up at Gondar University hospital pediatric seizure clinic participated in the study with a response rate of $98.1 \%$. Out of the total participants, $158(60.8 \%)$ were male sex, with a mean age of $10.5 \pm 2.7$ years (Table 1 ).

Table1.Socio-demographic and family related characteristics of participants $(n=260)$, university of Gondar referral hospital 


\begin{tabular}{|c|c|c|}
\hline & frequency & Percent (\%) \\
\hline Age & 184 & 70.8 mean age \\
\hline 7-11 & 76 & $29.2 \quad 10.5 \pm 2.7$ years \\
\hline \multicolumn{3}{|l|}{$\geq 12$} \\
\hline Sex & 158 & 60.8 \\
\hline Male & 102 & 39.2 \\
\hline \multicolumn{3}{|l|}{ Female } \\
\hline Religion & 214 & 82.3 \\
\hline Orthodox & 46 & 17.7 \\
\hline \multicolumn{3}{|l|}{ others } \\
\hline Ethnicity & 244 & 93.8 \\
\hline Amhara & 16 & 6.2 \\
\hline \multicolumn{3}{|l|}{ others } \\
\hline Is the mother alive & 239 & 91.9 \\
\hline Yes & 21 & 8.1 \\
\hline \multicolumn{3}{|l|}{ No } \\
\hline Is the father alive & 237 & 91.2 \\
\hline Yes & 23 & 8.8 \\
\hline \multicolumn{3}{|l|}{ No } \\
\hline Living arrangement & 222 & 85.4 \\
\hline -With both parents & 38 & 14.6 \\
\hline \multicolumn{3}{|l|}{-One parent or others } \\
\hline Seizure disorder in the family & 69 & 26.5 \\
\hline Yes & 191 & 73.5 \\
\hline \multicolumn{3}{|l|}{ No } \\
\hline Mental illness in the family & 41 & 15.8 \\
\hline Yes & 219 & 84.2 \\
\hline No & & \\
\hline
\end{tabular}

Pregnancy, delivery and childhood related factors 
One fourth, $69(26.5 \%)$, and $41(15.8 \%)$ of the children had family history of seizure disorder and psychiatric illness, respectively, while32 (12.3\%) had sever medical illness before the age of seven years (Table 2)

Table 2 Pregnancy, delivery and childhood related characteristics of participants $(n=260)$, University of Gondar referral hospital

\begin{tabular}{|c|c|c|}
\hline & frequency & Percent (\%) \\
\hline Mother's health during pregnancy & 251 & 96.5 \\
\hline Healthy & 3 & 1.5 \\
\hline Acute illness & 6 & 2.3 \\
\hline \multicolumn{3}{|l|}{ Chronic illness } \\
\hline Substance abuse during pregnancy & 256 & 98.5 \\
\hline Yes & 4 & 1.5 \\
\hline \multicolumn{3}{|l|}{ No } \\
\hline Place of delivery & 190 & 73.1 \\
\hline Home & 70 & 26.9 \\
\hline \multicolumn{3}{|l|}{ Health institution } \\
\hline Mode of delivery & 219 & 84.2 \\
\hline SVD & 28 & 10.8 \\
\hline Instrumental delivery & 13 & 5 \\
\hline \multicolumn{3}{|l|}{ CS } \\
\hline Birth complication & 26 & 90 \\
\hline Yes & 234 & 10 \\
\hline \multicolumn{3}{|l|}{ no } \\
\hline Feeding & 244 & 93.8 \\
\hline Exclusive breast feeding & 3 & 1.2 \\
\hline Formula & 13 & 5 \\
\hline \multicolumn{3}{|l|}{ Mixed } \\
\hline Health problem before the age of $7 \mathrm{yrs}$ & 228 & 87.7 \\
\hline Yes & 32 & 12.3 \\
\hline no & & \\
\hline
\end{tabular}




\section{Seizure related factors}

Most, 224(86.2\%) of the children were diagnosed with generalized tonic- clonic seizure; among $135(51.9 \%)$ participants' seizure started suddenly. More than half $173(66.5 \%)$ of the children had seizure at least once per month before they started medication. Seizure was not controlled among more than half $142(54.6 \%)$ of the participants (Table 3 ).

Table 3 Seizure related factors ( $n=260)$, University of Gondar referral hospital

\begin{tabular}{|lll|}
\hline & frequency & Percent (\%) \\
\hline Age of set & 152 & 58.5 \\
Before age 7 & 108 & 41.5 \\
Age 7 above & & \\
\hline One set & 135 & 51.9 \\
Sudden & 125 & 48.1 \\
gradual & & \\
\hline Seizure type & 224 & 86.2 \\
Grandmal & 36 & 13.8 \\
others & 142 & 54.6 \\
\hline Last seizure & 118 & 45.4 \\
Within 6 months & & \\
Before 6 months & 181 & 69.6 \\
\hline Number of medication & 79 & 30.4 \\
Single & & \\
combination & & \\
\hline
\end{tabular}

\section{Prevalence of ADHD}

As shown in Figure 1, the magnitude of ADHD among epileptic children was 115(44.2) with a confidence interval of (38.1-50.5), out of which only $3(2.6 \%)$ were detected as having mental health problems by the clinician. The predominant $96(61.1 \%)$, subtype was inattentive followed by the hyperactive subtype $61(38.9 \%)$.

Fig.1Magnitude of attention deficit hyperactivity disorder (ADHD) 


\section{Factors associated with ADHD}

Among all the covariate age group, sex, mothers and fathers, living arrangements, family history of seizure, and mental illness, seizure type, onset and status were found to have $p$-value less than 0.2 in the bi-variable logistic regression and considered for the multiple logistic regression model. The model goodness of fit was tested using the Hosmer and Lemeshow test and the p-value was found to be 0.719 and revealed the model was good.

Factors significantly associated with depression were male sex, $(A O R=2.70 \mathrm{Cl}$ : 1.46-4.97), family history of seizure disorder, $(\mathrm{AOR}=2.42 \mathrm{Cl}: 1.26-4.65)$, family history of other mental illnesses, $(A O R=4.14(1.76-$ 9.68), sudden onsets of seizure(AOR= 2.37(1.32-4.27) and uncontrolled seizures, 2.55(1.41-4.61) (Table 4)

Table 4. Factors associated with ADHD among children with seizure disorders at University of Gondar referral hospital 


\begin{tabular}{|c|c|c|c|c|}
\hline & \multicolumn{2}{|c|}{ ADHD } & \multirow[t]{2}{*}{$\operatorname{COR}(95 \% \mathrm{Cl})$} & \multirow[t]{2}{*}{$\mathrm{AOR}(95 \% \mathrm{Cl})$} \\
\hline & Yes & No & & \\
\hline Age & 86 & 98 & $1.42(0.82-2.45)$ & $1.57(0.82-3.02)$ \\
\hline $7-11$ & 29 & 47 & 1.00 & 1.00 \\
\hline \multicolumn{5}{|l|}{$\geq 12$} \\
\hline Sex & 86 & 72 & $3.01(1.76-5.11)$ & $2.70(1.46-4.97) *$ \\
\hline $\begin{array}{l}\text { Male } \\
\text { female }\end{array}$ & 29 & 73 & 1.00 & 1.00 \\
\hline Mother alive & 100 & 139 & $3.41(1.54-4.82)$ & $0.659(0.16-2.17)$ \\
\hline Yes & 15 & 6 & 1.00 & 1.00 \\
\hline \multicolumn{5}{|l|}{ No } \\
\hline Father alive & 98 & 139 & 4.02(1.53-10.5) & $0.38(0.87-1.65)$ \\
\hline Yes & 17 & 6 & 1.00 & 1.00 \\
\hline \multicolumn{5}{|l|}{ No } \\
\hline Living arrangement & 90 & 25 & $2.82(1.37-5.81)$ & $1.14(0.38-3.61)$ \\
\hline Both parents & 25 & 13 & 1.00 & 1.00 \\
\hline \multicolumn{5}{|l|}{ One parent or others } \\
\hline FFamilyHx of seizure & 43 & 26 & $2.73(1.55-4.82)$ & $2.42(1.26-4.65) *$ \\
\hline Yes & 72 & 119 & 1.00 & 1.00 \\
\hline \multicolumn{5}{|l|}{ No } \\
\hline Family $\mathrm{Hx}$ of mental illness & 31 & 10 & $4.98(2.32-10.68)$ & $4.14(1,76-9.68) *$ \\
\hline Yes & 84 & 135 & 1.00 & 1.00 \\
\hline \multicolumn{5}{|l|}{ No } \\
\hline Seizure type & 107 & 117 & 3.2(1.39-7.33) & $1.86(0.73-4.75)$ \\
\hline GTC & 8 & 28 & 1.00 & 1.00 \\
\hline \multicolumn{5}{|l|}{ Others } \\
\hline Seizure onset & 74 & 61 & $2.48(1.50-4.11)$ & $2.37(1.32-4.27) *$ \\
\hline Sudden & 41 & 84 & 1.00 & 1.00 \\
\hline Gradual & & & & \\
\hline Seizure status & 75 & 67 & $2.18(1.32-3.61)$ & $2.55(1.41-4.61)^{\star}$ \\
\hline
\end{tabular}




\section{$*=\mathrm{P}$ value $<0.05$}

\section{Discussion}

The prevalence of ADHD among children with seizure disorder was $44.2 \%$ (95\% Cl: $38.1 \%, 50.5 \%)$ which is in line with the result of a study conducted in China(7). The current estimate is by far higher than the results of the studies conducted in Korea(5), Israel(8), Brazil(9), Norway(11), USA(12), Central china (14) and India(15). The differences were due to variations in sample sizes, study populations and screening tools. The sample sizes in the other studies were lower than that of the current study. The studies conducted in Korea and India used DSM-IV criterion which was a diagnostic manual, and epileptic children were observed to confirm the presence of ADHD symptoms. In addition they excluded children who had intellectual disability, other psychiatric disorders and chronic medical illnesses. In the USA, only children with new onsets of epilepsy diagnosed in the past 12 months were taken.

The magnitude of ADHD in our work was lower than those of previous studies conducted in Iran (13) and Tanzania(16),perhaps due to sample size and assessment tool differences. The study conducted in Iran used highly sensitive child symptom inventory. Another study in Tanzania took a large sample and used a child behavioral checklist.

The current study was identified different factors that had associations with ADHD during the course of seizure disorders. Male sex was one of the associated factors of the magnitude of ADHD, a result in line with that of a study conducted in India(15). This was different from what was reported from Korea (5) and the USA(12).

The other factor that had a significant association with ADHD was family history of seizure disorder. If a child had a family history of seizure disorders, the illness would be very severe, and the severity of the seizure disorder might increase the risk of developing childhood psychiatric disorders, including ADHD. Previous studies we reviewed didn't assess family history of seizure disorder as an associated factor.

In contrast to a study in India(15), family history of psychiatric illness was significantly associated with the magnitude of ADHD among children with seizure disorders. That was evidenced by the role of genetic predisposition for psychiatric disorders. Other studies didn't assess family history of psychiatric disorder as a contributing factor.

The other contributing factor was uncontrolled seizure. Children who had seizure episodes during the last six months, had more than two times increased risk for ADHD compared with children who were seizure free for more than six months, similar to the finding in India(15). It was however different what were reported from in Korea (5) and the USA (12) which showed that children's seizure status had no significant associations with the prevalence of ADHD. 
Sudden onset of seizure disorder is among the associated factors of the magnitude of seizure disorders. That was because when the onset is sudden the illness becomes severe. This result was different from what was noted in USA, where seizure onsets were not significant associated factor of the prevalence of ADHD.

Like studies conducted in Korea (5), USA (12)and India(15) age in this work had no significant association with the magnitude of ADHD. Number of antiepileptic drugs, age at onset and prolonged antiepileptic treatments were not associated significantly with ADHD in the current study in distinction from the result of a study conducted in China(7).

In contrast to the studies conducted in Korea (5) and Tanzania(16),type of epilepsy syndrome had no significant association with the magnitude of ADHD in our study. The institution based cross-sectional design of our study has limited its generalizability as well as its capacity of establishing temporal relationships, respectively.

\section{Conclusion And Recommendation}

The magnitude of ADHD among children with seizure disorders was relatively higher in this attempt than most study reports worldwide. Despite this high prevalence only a few number of children were diagnosed as having ADHD. Male sex, sudden onsets of seizure, family history of seizure and that of other psychiatric disorders as well as uncontrolled seizures were factors that increased the odds of ADHD. To Increasing early detection and management of co-morbid ADHD training should be given about mental health problems for health professional working in pediatric seizure clinic. Treating seizure disorder appropriately and controlling seizure could minimize the risk of having co-morbid ADHD.

\section{Declarations}

\section{Ethical approval and consent to participate}

Ethical clearance was obtained from the University of Gondar Ethical Review committee (IRB). A written support letter was secured from the hospital chief executive officer and medical director. Verbal and written consent was sought from participants' parents or care givers' before starting data collection. Parents of children confirmed to have ADHD were advised and linked to the psychiatry clinic of the hospital.

\section{Availability of data and materials}

The datasets generated used and/or analyzed during the current study are available from the corresponding author on reasonable request.

\section{Competing interest}


There is no any competing interest

\section{Funding}

This study was funded by University of Gondar, Research and community service vice president office.

\section{Acknowledgments}

All the authors of this paper would like to acknowledge University of Gondar, Research and community service office for their financial support. We also appreciate data collectors, study participants and staffs of University of Gondar referral hospital pediatric chronic illness clinic.

\section{Author's contributions}

HM was initializing and designed the study. HM,NY,TE contribute in data collection and analysis. HM wrote the paper. HM,NY,TE edit the paper.

\section{Abbreviations}

$\mathrm{AOR}=$ adjusted odd ratio

$A D H D=$ Attention Deficit Hyperactivity Disorder

$\mathrm{CD}=$ conduct disorder

$\mathrm{COR}=$ crude odd ratio

$\mathrm{DBD}=$ disruptive behavioural disorder

$\mathrm{ODD}=$ oppositional defiant disorder

$\mathrm{OR}=$ odd ratio

SPSS = statistical package for social sciences

\section{References}

1.American psychiatric association (APA). Diagnostic and Statistical Manual of Mental Disorders. 2000.

2.American psychiatric association (APA). Diagnostic and statistical manual of mental disorders. 1994.

3.Dunn DW, Harezlak J, Austin J. ADHD and epilepsy in childhood. Developmental Medicine and Child Neurology 2003;45(1): 50-54. 
4.Bennett-Back.O, Keren A,Zelnik N. Attention-deficit hyperactivity disorder in children with benign epilepsy and their siblings. Pediatric Neurology, 2011;44, 187-192

5.Russ.SA, Larson K, Halfon N. A national profile of childhood epilepsy and seizure disorders. AM Acad Pediatrics. 2012;129, 256-264.

6.Aldenkam, Albert $P$ et al. Optimizing therapy of seizures in children and adolescents with ADHD. Neurology. 2006;67 (suppl 4): 49-51.

7.David W, Dunn A,Joan K,Austin B. Differential diagnosis and treatment of psychiatric disorders in children and adolescents with epilepsy. Epilepsy Behav. 2004;vol 5(Supp/ 3): 10-17.

8.Gun-Ha Kim,Ji Yeon Kim, Jung Hye Byeon,et al. attention deficite hyperactivity disorder in epileptic children; journal of korean medical sciences. 2012;27(10):1229-1232.

9.Han .Y, Qin Jiang YW, et al.Co-morbidity of attention deficit hyperactivity disorder in children with epilepsy. Chinese journal of contemporary pediatrics. 2012;14(2);89-92. .

10.Rony.C Yehuda.S, Avinoam S,et al. Prevalence of epilepsy and attention deficit hyperactivity disorder Journal of child neurology. 2013;28(1).

11.Casella B; Julio AS. Attention deficit and hyperactivity disorder in people with epilepsy: diagnosis and implications to the treatment. Arq Neuro-PsiquiatrSão Paulo. 2010;68(1): 107-114.

12.Davies S,Heyman I, HI. Goodman R. A population survey of mental health problems in children with epilepsy. Developmenta Medicine and Child Neurolgy. 2003,45 (5):292-295.

13.Kristine A, Jocelyne C, et al. Psychiatric symptoms in Norwegian children with epilepsy aged 8-13 years: Effects of age and gender? Epilepsia. 2011;52(7) 1231-1238.

14.Jana E, Ryann.W, Sheth R,Caplan R. Psychiatric comorbidity in children with new onset epilepsy. Developmental Medicine \& Child Neurology. 2007;49: 493-497.

15.Mahab M, Ebrahimi Moghadam H, Mirhashemi M. Incidence of Mental Disorders in Epileptic Children between 6 to 12 Years Old. Med Pharm Res. 2013;3(2): 43-46.

16. Qin Zhao et al. behavioural problem in children with epilepsy and Attention deficit hyperactivity disorder in central china. Epilepsy Behav. 2018.

17.Anita C, Gulati S, Sagar R, Sankhyan N. Childhood epilepsy and ADHD comorbidity in an Indian tertiary medical center outpatient population. Scientific reports, . 2018;8(2670).

18.Burton K, Rogathe J, Hunter E, Burton M et al. Behavioral co morbidity in Tanzanian children with epilepsy: a community based case control study. Developmental Medicine and child Neurology 2011;53:1135-1142. 
Figures

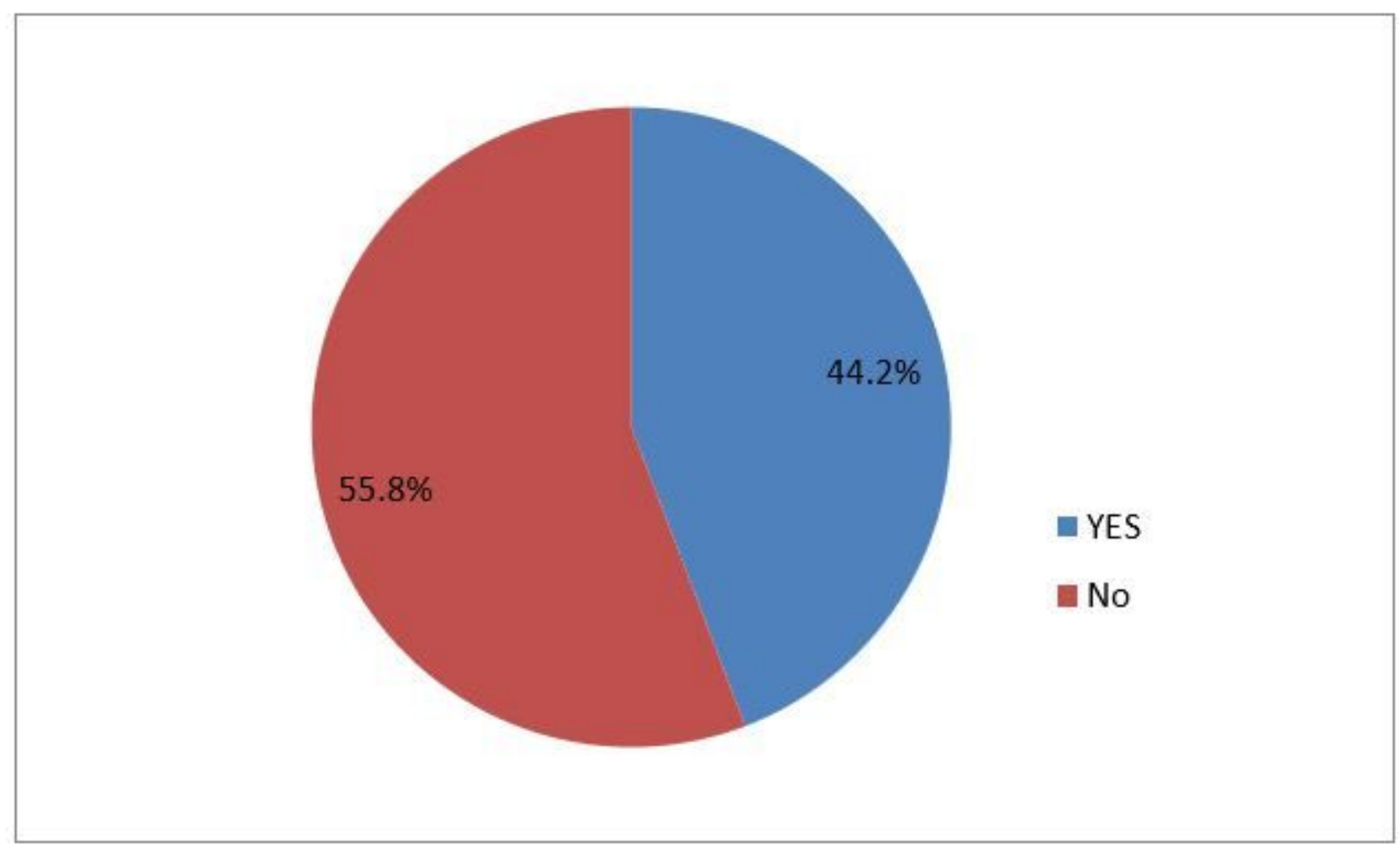

Figure 1

magnitude of attention deficit hyperactivity disorder 